\title{
Effects of interpolating a secondary task during the intertrial interval of a concept identification problem
}

\author{
RAYMOND M. WHITE, JR., JOHN R. WOODS, and WILLIAM WOZNIAK \\ Miami University, Oxford, Ohio 45056
}

\begin{abstract}
Several tasks were interpolated during the intertrial interval (ITI) of a concept identification (CI) task. In Experiment I, 234 subjects were required to count backwards by threes, emit a sibilant, or to refrain from thinking after all responses, after correct responses, or after errors. Counting backwards interfered with performance, but only if it occurred after errors. Stimulus and feedback information was either withheld, as in Experiment I, or made available during the ITI in Experiment II. Results of the data from 280 subjects indicated that counting backwards interfered with performance only when interpolated after errors, when stimulus-feedback information was withheld, but had an equivalent effect after errors and correct responses when stimulus-feedback information was available during ITI, indicating that different strategies were induced by the presence of such information.
\end{abstract}

It has been established repeatedly that the intertrial interval (ITI) is an important variable in concept identification (Cl) problems (e.g., Bourne, Guy, Dodd, \& Justesen, 1965; White \& Schmidt, 1972). As the ITI increases in duration, performance improves, but only to a point, if the stimulus and feedback are not available during the ITI. Variations in the stimulus and other intervals constituting a trial have been shown not to be related to performance.

The duration of the ITI can also be made contingent on the type of feedback which precedes ITI. Bourne, Dodd, Guy, and Justesen (1968) set the duration of ITI to be nearly optimal or clearly suboptimal after positive and negative feedback. Four conditions were thereby generated. In one condition (I), all ITIs were suboptimal, while in another, all ITIs were nearly optimal (IV). The other conditions consisted of near-optimal ITIs after positive feedback and suboptimal ITIs after negative feedback (II) or the reversed combination of ITIs and feedback (III). The results of the experiment showed the following ordering of the conditions from best to worst: IV = III $=$ II $>$ I. In general, the duration of ITIs appeared to be importantly related to performance whether optimal intervals occurred after positive or negative feedback, but the observed effects were of somewhat greater magnitude after negative feedback.

It is clear that processes important to the solution of a CI problem are activated during ITI, and the

The research reported herein was supported by grants from the Faculty Research Committee at Miami University ot the first author. The authors wish to express their appreciation to Ann Helberg, Jeff Lehman, Carolyn Maxwell, Pat Pethtel, Linda Shahan, and Juli Smith, who assisted in the preparation of the experiments and in data collection and analysis. The first author also expresses his appreciation to the Department of Psychology at the University of Utah for its support during the summer of 1974. possibility exists that the nature of the process differs after positive and negative feedback. In fact, some theories (e.g., Levine, 1970) explicitly distinguish processes according to the type of feedback produced by the response. Thus, it is necessary to manipulate variables systematically and independently for positive and negative feedback.

The variation of ITIs and their contingent relationship to feedback provides direct evidence as to the existence of processes, but provides only indirect evidence of the identity of the processes. Therefore, additional methods are needed to augment the data provided by ITI manipulations. One promising method involves the interpolation of a secondary task (e.g., Bower, 1972) during critical periods. To the extent that such a task initiates processes that are similar to the primary task of solving a $\mathrm{CI}$ problem or occupies space in working memory ordinarily used during solution of the primary task, performance ought to be affected.

It was the purpose of the present experiments to explore the effects of interpolating various types of secondary tasks during ITI on performance in a CI task, to establish whether the effects of the interpolated tasks are dependent on type of feedback, and to assess whether other standard variables such as the presence of the previously classified stimulus during ITI alters the effects of the interpolated task.

\section{EXPERIMENT I}

\footnotetext{
Method

Subjects and design. A total of 234 male and female college student subjects were assigned randomly in equal numbers to one of 26 conditions of the experiment. The subjects were volunteers, primarily from introductory psychology classes at Miami University. Of these 234 subjects, 31 were unable to solve the experimental problem within 160 trials.
} 
Table 1

Mean Number of Trials to Criterion and Standard Deviations Over All Subjects in Each Condition of Experiment I

\begin{tabular}{|c|c|c|c|c|c|}
\hline \multirow[b]{2}{*}{ Response } & & \multicolumn{4}{|c|}{ Time of Interpolation } \\
\hline & & Both & Incorrect & Correct & None \\
\hline & & \multicolumn{4}{|c|}{ Problem 1} \\
\hline Count & $\begin{array}{l}\text { Mean } \\
\text { SD }\end{array}$ & $\begin{array}{r}131.89 \\
45.20\end{array}$ & $\begin{array}{l}99.22 \\
47.94\end{array}$ & $\begin{array}{l}48.33 \\
43.96\end{array}$ & \\
\hline Hiss & $\begin{array}{l}\text { Mean } \\
\text { SD }\end{array}$ & $\begin{array}{l}62.11 \\
49.98\end{array}$ & $\begin{array}{l}46.00 \\
35.36\end{array}$ & $\begin{array}{l}36.11 \\
17.87\end{array}$ & \\
\hline Not Think & $\begin{array}{l}\text { Mean } \\
\text { SD }\end{array}$ & $\begin{array}{l}47.77 \\
34.92\end{array}$ & $\begin{array}{l}58.11 \\
44.97\end{array}$ & $\begin{array}{l}39.44 \\
25.27\end{array}$ & \\
\hline \multirow[t]{2}{*}{ Control } & $\begin{array}{l}\text { Mean } \\
\text { SD }\end{array}$ & $\begin{array}{l}76.22 \\
40.25\end{array}$ & $\begin{array}{l}80.78 \\
40.46\end{array}$ & $\begin{array}{l}49.88 \\
24.48\end{array}$ & $\begin{array}{l}63.33 \\
56.99\end{array}$ \\
\hline & & \multicolumn{4}{|c|}{ Problem 2} \\
\hline Count & $\begin{array}{l}\text { Mean } \\
\text { SD }\end{array}$ & $\begin{array}{r}118.22 \\
44.38\end{array}$ & $\begin{array}{r}107.89 \\
45.65\end{array}$ & $\begin{array}{l}89.11 \\
54.99\end{array}$ & \\
\hline Hiss & $\begin{array}{l}\text { Mean } \\
\text { SD }\end{array}$ & $\begin{array}{r}102.67 \\
52.72\end{array}$ & $\begin{array}{l}79.33 \\
54.72\end{array}$ & $\begin{array}{l}67.33 \\
44.16\end{array}$ & \\
\hline Not Think & $\begin{array}{l}\text { Mean } \\
\text { SD }\end{array}$ & $\begin{array}{l}76.56 \\
48.84\end{array}$ & $\begin{array}{l}71.33 \\
26.64\end{array}$ & $\begin{array}{l}98.22 \\
50.47\end{array}$ & \\
\hline Control & $\begin{array}{l}\text { Mean } \\
\text { SD }\end{array}$ & $\begin{array}{l}92.33 \\
46.46\end{array}$ & $\begin{array}{l}86.11 \\
48.46\end{array}$ & $\begin{array}{r}103.78 \\
49.73\end{array}$ & $\begin{array}{l}52.56 \\
30.94\end{array}$ \\
\hline
\end{tabular}

The design of the experiment may be described as a 4 by 3 by 2 factorial with two additional external control groups. The four-level variable was defined as the type of response interpolated during the IT1. The subjects were instructed to count backwards by threes from some two-digit number, to emit a sibilant response, or to refrain from thinking about the solution to the problem. The fourth level was a control condition in which the subject was not instructed regarding the activity to be engaged in during the ITI. For the control conditions, rather than assigning the subject a response to be made during the ITI, the ITI was set at $1 \mathrm{sec}$ to make the condition comparable to the case where subjects in other conditions were counting, hissing, or not thinking. Thus, the ITIs were set at $1 \mathrm{sec}$ after both correct and incorrect responses. such a control condition being equated with the conditions in which a response was interpolated after each feedback signal. In the other cases. conditions were equated by aligning the proper control group with the experimental groups so that the ITI was set at $1 \mathrm{sec}$ after the appropriate feedback signal where the experimental groups were interpolating a response after comparable feedback.

The three-leveled variable was defined by the time the response was to be interpolated. The subject was instructed to respond appropriately after each feedback signal, after correct responses, or after errors.

The third variable was identified as the problem the subject was required to solve. For one problem. the conjunction of color and size of geometric figures served as the dimensions relevant to problem solution, while for the second problem, form and number of geometric figures were relevant. The two external control groups were defined by the problem to which they were assigned, as described above; in addition, the ITIs were not filled with any required activity.

Material and apparatus. The training and test problem stimuli were geometric figures prepared as $5.08 \times 5.08 \mathrm{~cm}$ slides. The geometric figures differed in color (red or green), size (small or large). form (square or triangle), number of figures (1 or 2), and background texture (speckled or crosshatched). The slides were rear-projected onto a screen immediately in front of the subject by means of a Carousel projector. The slides were arranged in the projector tray so that the entire population of 32 slides was shown prior to the presentation of eight additional slides needed to fill the tray. Blank slides appeared between each stimulus. The slides were ordered so that any given classificatory response would be correct no more than on three consecutive occasions; otherwise, the slides were randomiy selected from the population.

The apparatus which controlled the slide presentations, timed the various intervals, and controlled feedback was similar to one described in detail by Bourne and Haygood (1959). To recap briefly, the subject responds by pressing a button on a panel immediately in front of him, thus indicating his guess as to the correct classification of the stimulus. The stimulus is removed from the screen and feedback in the form of an amber light above the correct response button is activated for $1 \mathrm{sec}$. As soon as the feedback interval is over, the ITI starts and continues until the next slide is presented.

Procedure. The subjects were tested individually. Upon entering the laboratory, the subject was seated in front of the response panel and rear-projection screen. A routine set of instructions was then read to the subject. The instructions defined the stimulus population, illustrated the respense requirements of the task and emphasized that a conjunction of two characteristics of the slides determined the assignment of the slides to one of the four response categories. Care was taken to avoid suggesting solution modes during the instructions. Following the verbal instruction, the subject was given a sample problem to practice, the purpose of the task being to familiarize the subject with the apparatus and the type of material being classified. The task consisted of the presentation of six stimuli from the above-mentioned population; the stimuli were chosen so that all levels of all stimulus dimensions were illustrated and, thus, all four response categories were filled by at least one stimulus. As in the experimental problem, the stimulus interval was subject-determined and feedback occurred for $1 \mathrm{sec}$. The ITIs were set at $10 \mathrm{sec}$. Upon completing the practice problem, the subjects were shown the correct solution to the problem by the experimenter verbalizing the solution; e.g., one figure and speckled goes with Response Button 1, two figures and speckled goes with Response Button 2, etc. Following the presentation of the solution to the practice problem, those subjects who were to interpolate a response during ITIs were instructed as to what response to make and how the response was to be made. In the cognitive instruction condition, the subjects were told that the instruction to not think meant that the subject was not to think about the solution to the problem.

A metronome, set at 40 beats $/ \mathrm{min}$, was used to pace the subjects who were counting backwards. The metronome was also running during the experimental problem for the subjects in all other conditions. The subjects in the counting condition were periodically urged by the experimenter to pace their counting with the metronome if they were failing to do so.

For the test problem, with the exception of some of the control groups, the ITls after all responses were set at $10 \mathrm{sec}$. Criterion of problem solution was 10 consecutively correct responses. All subjects were asked to give a verbal description of problem solution upon meeting criterion. The subjects were urged not to discuss the solution to the problen; each received a one-page description of the purpose, results, and implications of the experiment a few weeks after the experiment was completed.

\section{Results}

The mean number of trials to criterion was the measure selected for analysis after having determined that errors to criterion provided virtually identical results. The mean number of trials to criterion and the standard deviations for each experimental and control group are shown in Table 1 . Both solvers and nonsolving subjects' data are included in these summary statistics. An analysis of variance (e.g., Winer, 1962, p. 264) applied to the data in Table 2 showed significant effects due to time of interpolation, 
$F(3.202)=0.65$. type of response interpolated. $F(3.202)=5.37$. and problem, $F(1.202)=10.83$. and the Time of Interpolation by Problem interaction. $F(3.202)=5.01$. to be a significant source of variation. all with $p<.01$. An analysis of the data of solving subjects only showed virtually identical results and are not reported here.

The Newman-Keuls method of ordered. paired comparisons was conducted on the marginal means to ascertain which differences among the means due to type of interpolated response were significant. The results revealed that counting was associated with signiticantly more trials than hissing or "not thinking" (both ps $<.01$ ); all other differences were not significant. Analyses of the time of interpolation variable showed that interpolating a response on all trials increased trials to criterion more than not interpolating a response, or interpolating a response after correct responses only (both ps $<.01$ ). Interpolating a response after an incorrect response only increased trials to eriterion more than not interpolating a response $(\mathrm{p}<.05)$. Thus, the interpolation of a response after errors has a strong interfering effect in comparison to the effect of interpolating an identical response after correct responses.

Since the interaction of Type of Response by Time of Interpolation was predicted, an analysis of the simple main effects was also conducted. Significant difterences among the means were found only for the counting groups. Counting after all responses required more trials to solve than not counting or counting after correct responses (both $\mathrm{p}<.01$ ). Counting after incorrect responses required more trials than not counting $(p<.01)$. None of the other differences were significant at the .01 level. In summary, interpolating a response after positive and negative feedback interferes with performance, the effect being considerably stronger after negative feedback.

\section{EXPERIMENT II}

The results of Experiment I suggest that (a) to effectively interfere with the subject's ability to identify a concept. he must be engaged in some activity over which the experimenter has control and which involves some central. computing activity; (b) interpolating activity during ITI is a more effective means of manipulating the subject's behavior than manipulating the duration of ITIs; (c) processes involved in the identification of a concept are more susceptible to the interpolation of a secondary task during ITIs after negative than after positive feedback. although the evidence concerning the effects of interpolating after positive feedback are still not entirely clear. since interpolating a response on all trials ws. after negative feedback only did not produce a statistically significant effect; and (d) whether or not the subject engages in problem solving activity after positive or negative feedback, or both. depends on the difficulty of the problem. Whether or not the Time of Interpolation by Problem interaction is a reliable result was investigated in Experiment II.

Aside from the reliability questions of Experiment $\mathrm{I}$. one major question raised by that experiment is what the effects of counting backwards are. The answer is not immediately obvious because several effects can be postulated. On the one hand, the act of counting could remove from working memory any trace of the preceding stimulus. If that is the case, the subject would be unable to adjust his hypothesis with respect to the stimulus and feedback information. On the other hand, counting might block the subject's opportunity to formulate and test hypotheses altogether. Experiment II was directed to the question of whether counting erases the subject's memory for the preceding stimulus and feedback information or interferes with his ability to formulate hypotheses. To test the alternative interpretations, the presence of stimulus and feedback during ITI was manipulated. If counting erases stimulus and feedback information, then an interaction of Time of Interpolation by Stimulus-Feedback Information would be expected. That is, the ordering obtained in Experiment I would be expected in the case where the ITI was devoid of stimulus-feedback information; however, with stimulus-feedback information available, counting should have no effect and the four counting conditions should be equivalent. The absence of an interaction would seem to indicate that counting interferes with the ability of the subject to formulate and alter hypotheses.

\section{Method}

Subjects and design. A total of 280 male and femule undergraduate volunteers were assigned randomly. but in equal numbers. to one of 28 conditions of the experiment. Of the 280 subjects. 44 were unable to arrive at problem solution within 160 trials. The experiment, for purposes of statistical analyses, may be described as a 4 by 2 by 2 by 2 factorial with the folowing variables: time of interpolation (after all responses, after errors only, after corrects only, and control-no responses being interpolated); stimulus-feedback information (on vs. off during the ITI); type of interpolation (counting vs. timing); and problem (color and size or form and number). As in Experiment 1 . the control conditions received 1 -sec ITIs after all responses. $10 \mathrm{sec}$ after correct responses and $10 \mathrm{sec}$ after errors. or $10 \mathrm{sec}$ after all responses. The counting and timing conditions were equated in the same manner as in Experiment I.

Materials, apparatus, and procedure. The remaining methods were virtually identical to those of Experiment I. The sole exception was that for one-half of the subjects. the stimulus and feedback remained on during the entire ITI. Therefore, it was necessary to use 41 additional slides from the stimulus population described for Experiment I. For each problem, each stimulus was selected from the population before one of nine additional duplicates was selected. The first 40 slides were identical in form and order to those used in Experiment I. 
Table 2

Mean Number of Trials to Criterion and Standard Deviations for All Subjects in Each Condition of Experiment II

\begin{tabular}{|c|c|c|c|c|c|c|c|c|c|}
\hline \multirow[b]{2}{*}{ Response } & & \multicolumn{4}{|c|}{ Time of Interpolation } & \multicolumn{4}{|c|}{ Time of Interpolation } \\
\hline & & Both & Incorrect & Correct & None & Both & Incorrect & Correct & None \\
\hline & & \multicolumn{4}{|c|}{ Problem 1: Stimulus-Feedback On } & \multicolumn{4}{|c|}{ Problem 2: Stimulus-Feedback On } \\
\hline Count & $\begin{array}{l}\text { Mean } \\
\text { SD }\end{array}$ & $\begin{array}{r}102.60 \\
52.00\end{array}$ & $\begin{array}{l}51.20 \\
21.87\end{array}$ & $\begin{array}{l}70.10 \\
44.48\end{array}$ & & $\begin{array}{r}110.30 \\
46.23\end{array}$ & $\begin{array}{l}64.50 \\
45.34\end{array}$ & $\begin{array}{l}76.50 \\
35.21\end{array}$ & \\
\hline \multirow[t]{2}{*}{ Control } & $\begin{array}{l}\text { Mean } \\
\text { SD }\end{array}$ & $\begin{array}{l}56.40 \\
22.06\end{array}$ & $\begin{array}{l}71.50 \\
49.64\end{array}$ & $\begin{array}{l}33.60 \\
19.57\end{array}$ & $\begin{array}{l}37.40 \\
29.39\end{array}$ & $\begin{array}{r}115.40 \\
42.03\end{array}$ & $\begin{array}{l}85.40 \\
46.61\end{array}$ & $\begin{array}{l}77.80 \\
47.57\end{array}$ & $\begin{array}{l}32.50 \\
23.22\end{array}$ \\
\hline & & \multicolumn{4}{|c|}{ Problem 1: Stimulus-Feedback Off } & \multicolumn{4}{|c|}{ Problem 2: Stimulus-Feedback Off } \\
\hline Count & $\begin{array}{l}\text { Mean } \\
\text { SD }\end{array}$ & $\begin{array}{r}115.20 \\
51.46\end{array}$ & $\begin{array}{l}89.20 \\
67.22\end{array}$ & $\begin{array}{l}57.30 \\
42.93\end{array}$ & & $\begin{array}{r}131.20 \\
44.52\end{array}$ & $\begin{array}{r}109.10 \\
47.04\end{array}$ & $\begin{array}{l}70.80 \\
49.77\end{array}$ & \\
\hline Control & $\begin{array}{l}\text { Mean } \\
\text { SD }\end{array}$ & $\begin{array}{l}96.00 \\
62.46\end{array}$ & $\begin{array}{r}103.00 \\
49.93\end{array}$ & $\begin{array}{l}75.60 \\
58.77\end{array}$ & $\begin{array}{l}53.40 \\
29.65\end{array}$ & $\begin{array}{r}121.30 \\
53.29\end{array}$ & $\begin{array}{l}93.20 \\
31.09\end{array}$ & $\begin{array}{l}59.00 \\
37.24\end{array}$ & $\begin{array}{l}60.90 \\
47.74\end{array}$ \\
\hline
\end{tabular}

\section{Results}

The number of trials to criterion served as the dependent measure to which an analysis of variance was applied. Table 2 shows the means and standard deviations for each condition, including the data from both solving and nonsolving subjects. Treating the entire set of data as if they formed a factorial of four variables revealed reliable effects due to stimulusfeedback information, $F(1,248)=14.51$, time of interpolation, $F(3,248)=28.15$, and problem, $\mathrm{F}(1,248)=6.56$, all ps $<.01$.

A weighted-means analysis of variance on data of the solving subjects showed the interaction of Stimulus-Feedback Information by Time of Interpolation, $F(3,175)=3.06, p<.05$, to be reliable. The interaction is shown in Table 3.

Ordered, paired comparisons were conducted across the timing variable at separate levels of the stimulus-feedback variable. With stimulus and feedback information on during ITI, interpolation on all trials (I) increased trials. to reach criterion more than interpolating a response after negative feedback only (II), after positive feedback only (III), or not interpolating a response (IV). A summary of all the contrasts produced the following ordering of the conditions from best to worst: IV $>$ III $=$ II $>$ I. With stimulus and feedback information off during ITI, contrasts produced the following ordering: IV $=$ III $>$ II $=1$ (all ps $<.01$ ).

\section{DISCUSSION}

Generalizing over the two experiments, the results indicate that interpolating a counting task after negative feedback strongly interferes with the subject's ability to identify the relevant attributes of a concept problem, even though the classified stimulus and feedback are present during ITI. However, the effects of interpolating after positive feedback are more complex, depending particularly on the presence of the classified stimulus during ITI. If the classified stimulus is not available during ITI, the interpolated task appears to mildly interfere with performance; with the classified stimulus present during ITI, the effects of interpolating after positive feedback are as severe as an identical task interpolated after negative feedback.

Assuming that the effect of counting is to interfere with the subject's ability to retrieve and evaluate hypotheses, the data may be understood in the context of hypothesis sampling theory, a set of theories which is being applied to $\mathrm{CI}$ data with considerable frequency (e.g., Brown, 1974). In this context, it is assumed that the subject initially samples several hypotheses concerning the relevant attributes of the problem. These hypotheses are then evaluated against the information provided by the stimulus and feedback. Following Levine (1970), if negative feedback is received, the subject returns the sample of hypotheses to long-term memory and takes a new set for consideration on the following trial. However, if positive feedback occurs, the sampled subset of hypotheses is revised to contain only those hypotheses which are consistent with the information provided.

Applying Levine's characterization of hypothesis sampling to the present experiment and assuming that the size of the hypothesis set is a variable in the system, it may be predicted that with stimulus and feedback absent during ITI, the subject is less likely to entertain as large a subset of hypotheses as when stimulus and feedback are available. In this case, the subject must remember the characteristics of the stimulus in forming a sample of hypotheses; with the stimulus absent during ITI, the subject is forced to remember not only those hypotheses which have been rejected, but also the characteristics of the classified

Table 3

Stimulus-Feedback Information $X$ Time of Interpolation Interaction for Solving Subjects Only of Experiment II

\begin{tabular}{|c|c|c|c|c|}
\hline \multirow{2}{*}{$\begin{array}{l}\text { Stimulus- } \\
\text { Feedback }\end{array}$} & \multicolumn{4}{|c|}{ Time of Interpolation } \\
\hline & Both & Incorrect & Correct & None \\
\hline On & 84.91 & 60.70 & 59.47 & 34.95 \\
\hline Off & 76.05 & 80.81 & 55.19 & 51.74 \\
\hline
\end{tabular}

Note-Values are mean trials to criterion. 
stimulus. Thus, to minimize memory load, the subject might restrict the size of his hypothesis set to, say, two hypotheses (one for each relevant dimension). If this were the case, the effect of interpolating a counting task after positive feedback would be negligible. However, with stimulus and feedback available during ITI, the working hypothesis set should generally increase in size because, with such an artificial memory aid, the subject knows which hypotheses are potentially correct, and can sample accordingly. Interpolating a counting task after positive feedback under these circumstances ought to interfere with performance more severely since working memory contains a large set of hypotheses, the likelihood being greater that some of the hypotheses in the set will be lost because of the attention being devoted to the counting task. Since negative feedback causes the subject to return to long-term memory for a new set of hypotheses, interpolating a counting task after errors ought to produce substantial interference, regardless of whether stimulus and feedback are present.

A secondary purpose of the research was to explore the method of interpolating a secondary task during ITI. It is clear that such a method is effective in manipulating behavior in CI tasks, yet the large variances within treatments required large samples to illustrate effects. Perhaps a more efficient method would be to measure the effect of the primary task on a secondary task. For example, computation errors on, or speed of solving, an interpolated mathematical problem, or reaction times to various signals, might serve as effective dependent measures.

\section{REFERENCES}

Bourne, L. E., JR., Dodd, D. H., Guy, D. E., \& Justesen, D. R. Response-contingent intertrial intervals in concept identification. Journal of Experimental Psychology, 1968, 76, 601-608.

Bourne, L. E., JR., Guy, D. E., Dodd, D. H., \& Justesen, D. R. Concept identification: The effects of varying length and informational components of the intertrial interval. Journal of Experimental Psychology, 1965, 69, 624-629.

Bourne, L. E., JR., \& HAYgood, R. C. The role of stimulus redundancy in the identification of concepts. Journal of Experimental Psychology, 1959, 58, 232-238.

BowER, G. H. Mental imagery and associative learning. In L. W. Gregg (Ed.), Cognition in learning and memory. New York: Wiley, 1972. Pp. 51-88.

Brown, A. S. Examination of hypothesis-sampling theory. Psychological Bulletin, 1974, 81, 773-790.

LeviNe, M. Human discrimination learning: The subset sampling assumption. Psychological Bulletin, 1970, 74, 397-404.

White, R. M., JR., \& SChMidt, S. W. Preresponse intervals versus post-informative feedback intervals in concept identification. Journal of Experimental Psychology, 1972, 94, 350-352.

WINER, B. J. Statistical principles in experimental design. New York: McGraw-Hill, 1962.

(Received for publication January 6, 1975; revision received March 19, 1975.) 